\title{
DISCUSSION
}

\section{Pressures exerted by materials stored in silos: part I, coarse materials; part II fine powders}

\author{
G. E. BLIGHT (1986). Géotechnique 36, No. 1, 33-46; 47-56
}

\section{Dr A. Holmberg}

In part I the Author gives data on pressures observed in operating silos and compares them with pressures according to Janssen (arching) and to Rankine (no arching). The main material collected here in Table 1 shows no trends and gives no support to any theory. To the Author's material results have been added from a report by Holmberg in a special publication issued in August 1981 by the Danish Society for Structural Science and Engineering. The pressures given are derived from deformations including crack widths in the silo walls. They are included here as special data with a real strength $f_{\mathrm{c}}$ - say cohesioncharacterizing the stored material.

Ignoring the theories, for $f_{c} \approx 0$ as a mean $\delta K_{2}=0.41(1 \pm 0.21)$ (standard deviation) giving $0.41 \times 1.21=0.5$, which is apparently supported by the observations. Fig. 9 in part II, however, demonstrates great circumferential variations showing firstly that momentary high pressures at one point may correspond to low pressures at other points and secondly that forces from radial pressures have to be combined with bending moments caused by the circumferential variations. For a cylindrical concrete silo this is easily considered by placing the reinforcement in double layers according to the extremes of eccentricity. All this needs further study.

Figures 10 in part I and 3 in part II demonstrate the possible consequences of high values of $f_{i}$. The material stored does not need any lateral support at times. Alternatively, arching is so effective that material under the local abutments has no overload and therefore exerts no horizontal pressure. The vertical load in such a case may be the source of buckling and is then sometimes of greater importance than the horizontal pressure.

Dr R. P. McCabe, McCabe, Delaney \& Associates, Dublin

The structural failure of bulk storage silos for granular material has been recognized as being due to bursting pressure on the walls when the silos are emptying, but the Author has contributed little that identifies the problem except to describe the pressures he measured using $200 \mathrm{~mm}$ dia. pressure cells set in the silo walls. The Writer suggests that the Author has missed the point in his attempt to compute horizontal pressures using isolated pressure cells.

The following matters are relevant when studying pressurcs exerted in tall silos.

(a) The pattern of flow of the material must be established before an attempt is made to measure internal stresses in the material and pressures on the walls.

(b) The grading of the material is a greater function of pressure-uniform grading produces greater pressures than does irregular grading.

(c) Granular material in confined spaces tends to arch over small openings or other small surfaces such as the face of a pressure cell. It is the aggregate horizontal pressure at any specific section that should be measured if meaningful values are to be obtained. Hence silo walls with semicircular segments or collars linked with strain gauges or other such arrangement is indicated.

The research carried out by McCabe in 1970 outlined in McCabe (1974) clearly confirmed that four separate zones of flow occur in single-sized granular fill when discharging from cylindrical bottom opening silos. His findings were in close agreement with those of Deutsch \& Clyde (1967) and to a lesser extent with Chwetzoff (1960). The flow pattern in fig. 1 (part I) of the Author's Paper cannot be correct for granular material.

The flow patterns in the Writer's case were clearly identified using radioactive isotopes and were consistent for a variety of conditions using scale model silos and various grades of sand.

The Author has not identified flow patterns during any of his investigations, nor has he referred to grading of the material. It is not surprising that he obtained such a large scatter in horizontal pressures with isolated pressure cells. The Author also claims that in order for the contents to emerge from the silo, flow must converge towards the outlet' but if this occurred, in the way suggested, there would be a complete blockage at 


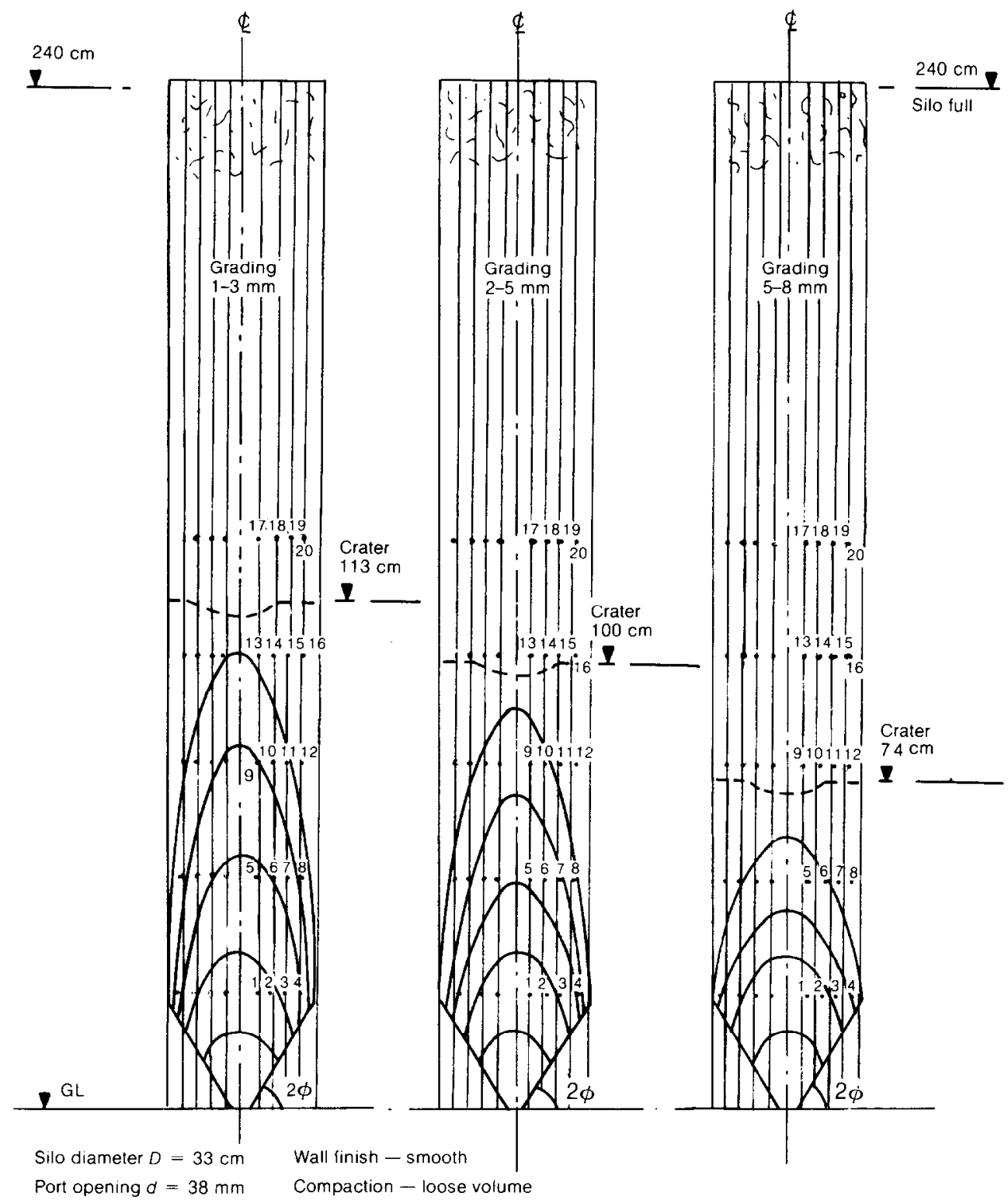

Fig. 1. Candle flame curves

the exit gate-like that in any football ground when the crowds try to storm the exit at the same time.

Plug flow in granular material must occur above the point of crater if the grading is uniform. Plug flow cannot be plug flow if the plug is fed off the top of the stored material'. The Author should reinvestigate this aspect. Janssen's theory is not correct for silo designs; that is why so many bulk silos containing granular material have failed-failure usually begins at the top of the conical slope forming the floor of the fill material. Janssen's work included the following assumptions which are not accurate for circular silos

$$
\begin{aligned}
\tan \delta & =p_{\mathrm{w}} / p_{\mathrm{h}}=\text { constant } \\
K & =p_{\mathrm{w}} / p_{\mathrm{v}}=\text { constant } \\
\lambda & =p_{\mathrm{h}} / p_{\mathrm{v}}=k / \tan \delta=\mathrm{constant}
\end{aligned}
$$

where $p_{\mathrm{w}}$ is the tangential stress on the wall, $p_{\mathrm{v}}$ is 


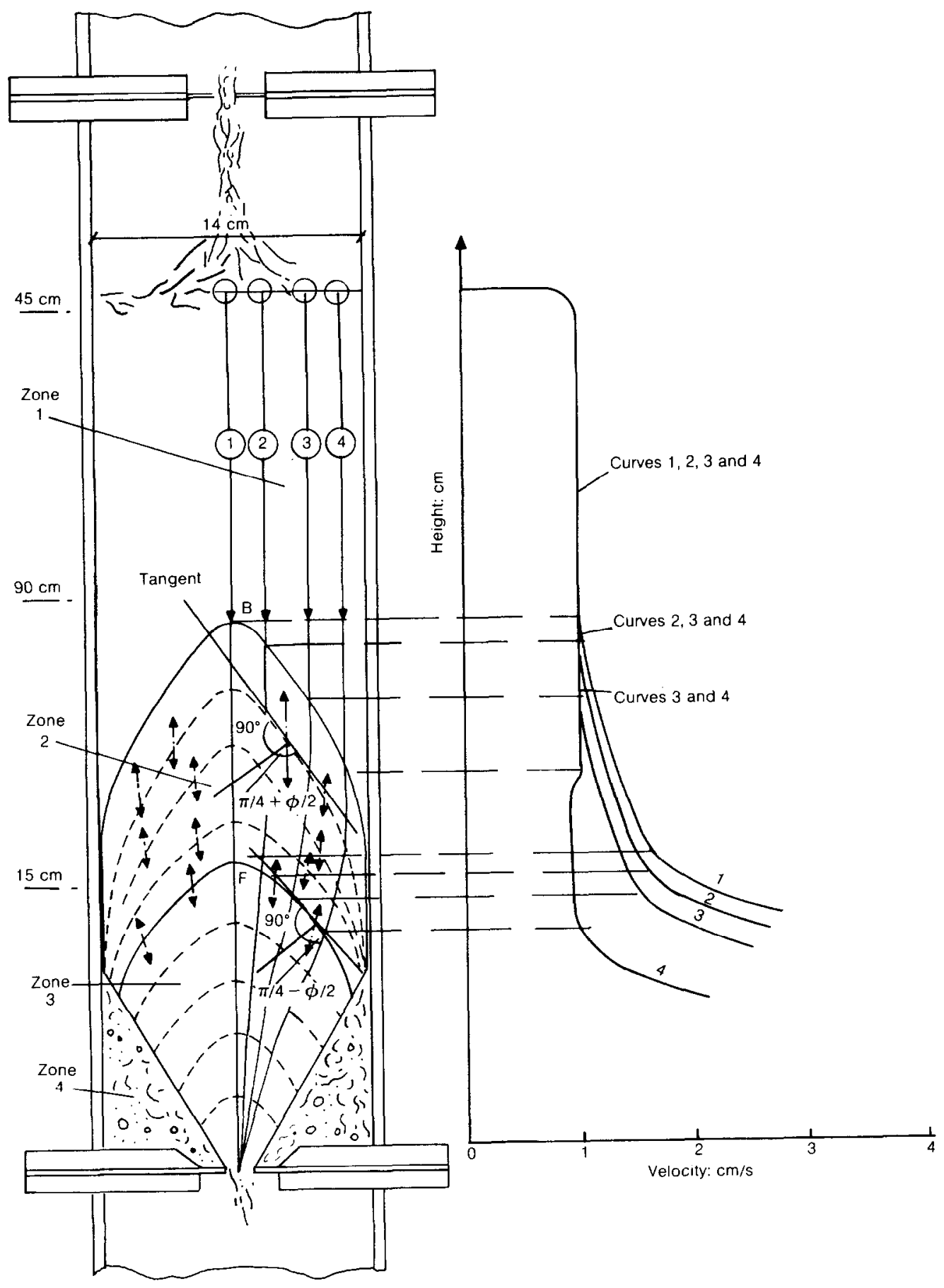

Fig. 2. Steady state (showing particle trajectory and angle of rupture) 
Table 1. Horizontal silo pressures $K \gamma z^{*}$

\begin{tabular}{|c|c|c|c|c|c|c|c|c|c|c|}
\hline Source & Material & $h / d$ & $\begin{array}{c}\phi: \\
\mathrm{deg}\end{array}$ & $\begin{array}{l}f_{\mathrm{c}}: \\
\mathrm{kPa}\end{array}$ & $K_{1}$ & $\delta K \dagger$ & $K_{2}$ & $\delta K \dagger$ & $K_{1} / K_{2}$ & Comment \\
\hline Blight, part I, fig. 6 & Coal & $2 \cdot 0$ & 40 & $\approx 0$ & 0.33 & $0 \cdot 46$ & 0.25 & 0.64 & 0.76 & \\
\hline Blight, part I, fig. 7 & Coal & 0.8 & 41 & $\approx 0$ & 0.26 & 0.49 & 0.33 & 0.47 & $1 \cdot 27$ & Partly funnel flow \\
\hline Blight, part I, fig. 8 & Ore & $1 \cdot 1$ & 42 & $\approx 0$ & $0 \cdot 16$ & 0.31 & $0 \cdot 22$ & 0.28 & 1.75 & \\
\hline Blight, part I, fig. 9 & Flour & $5 \cdot 5$ & 28 & $\approx 0$ & 0.19 & 0.35 & 0.23 & 0.58 & $1 \cdot 21$ & Extreme values \\
\hline Blight, part II, fig. 6 & Ash & $1 \cdot 2$ & 33 & $\approx 0$ & $0 \cdot 32$ & $0 \cdot 36$ & 0.37 & 0.35 & 1.06 & \\
\hline & & & & & & & & & & $\left(\frac{\delta K}{h / d}\right)_{\mathrm{t}}=0.19(1 \pm 0.54)$ \\
\hline Mean & & & & & 0.25 & & $0 \cdot 28$ & & $1 \cdot 21$ & $\left(\frac{\delta K}{h / d}\right),=0.31(1 \pm 0.50)$ \\
\hline Holmberg & Corn & $5 \cdot 7$ & 25 & 10 & $0 \cdot 10$ & 0.14 & $0 \cdot 14$ & 0.20 & 1.49 & Mean values \\
\hline
\end{tabular}

$* K_{1}$, filling; $K_{2}$, emptying; concrete walls.

+ Coefficient of variation.

the vertical stress, $p_{\mathrm{b}}$ is the horizontal stress and $\lambda$ is the wall friction. $\lambda$ is not constant over the silo height.

It is suggested that unless the pattern of flow is known together with the grading and density of the granular material no amount of manipulation of mathematical equations will suffice to obtain the correct values for pressures.

The research that McCabe carried out in 1971 revealed the following results using various grades of fill in model silos (McCabe, 1974) (a) candle flame curves or mitre of revolution profiles in the zone of dynamic equilibrium: these curves are isochons (Fig. 1)

(b) flow patterns, angle of rupture and velocity of descent of granular particles identified using radioactive isotopes: the partial opening in each case was central and could be varied in size for various test runs; the cone of exit was formed by the material using the natural angle required, which for each grading was $2 \phi$ (Fig. 2)

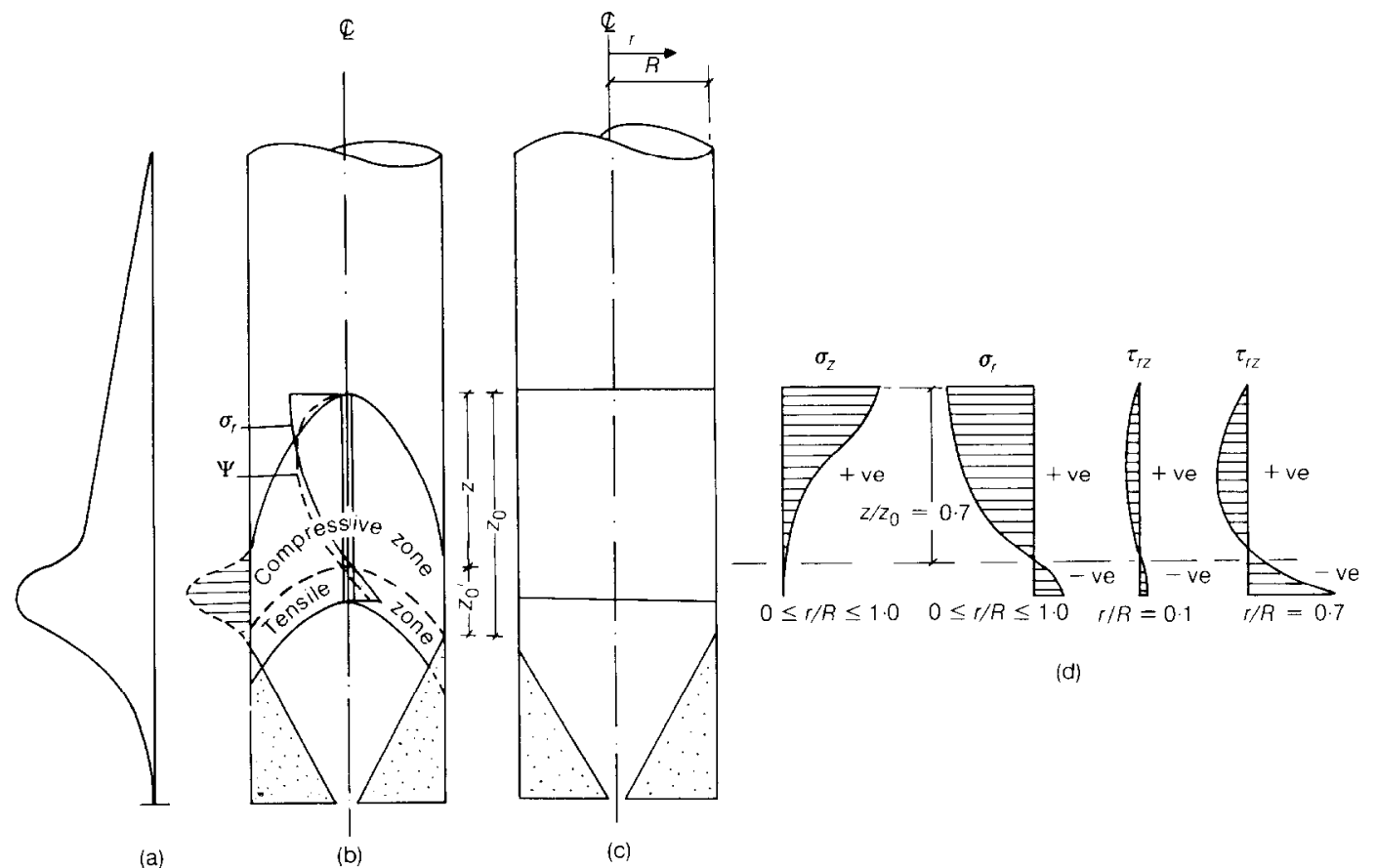

Fig. 3. Kepresentation of stress distribution: (a) pressure; (b) real domain; (c) transformed domain; (d) stress diagrams 


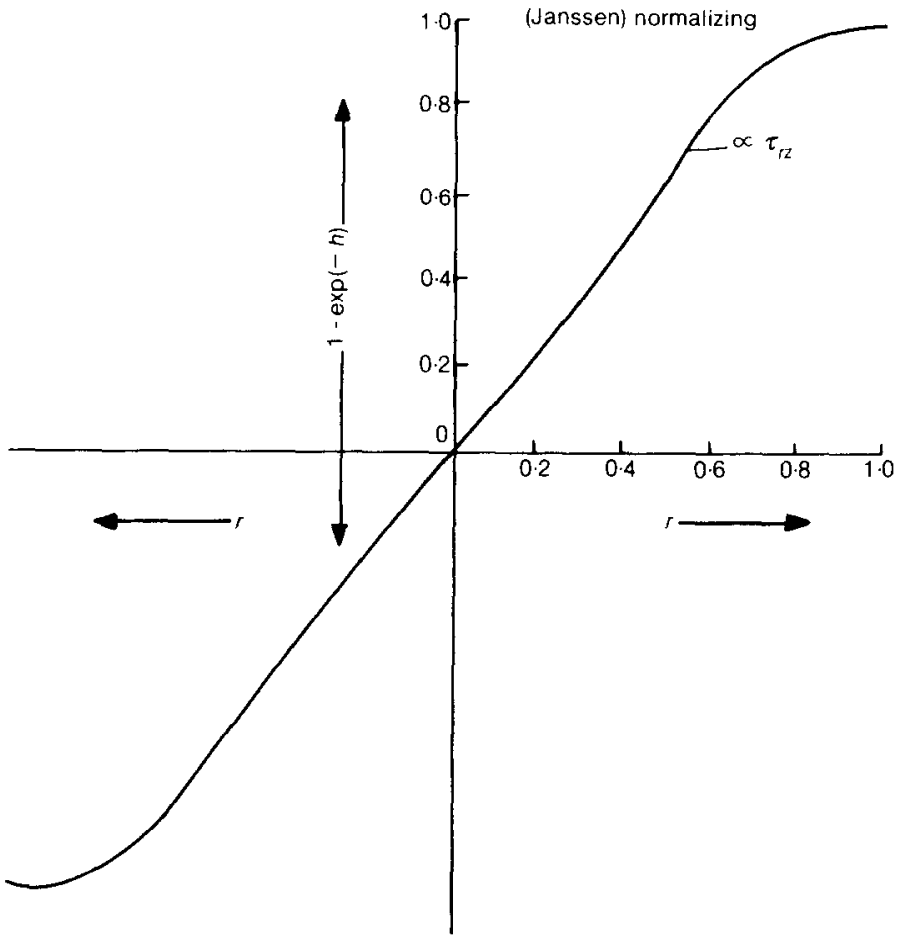

(a)
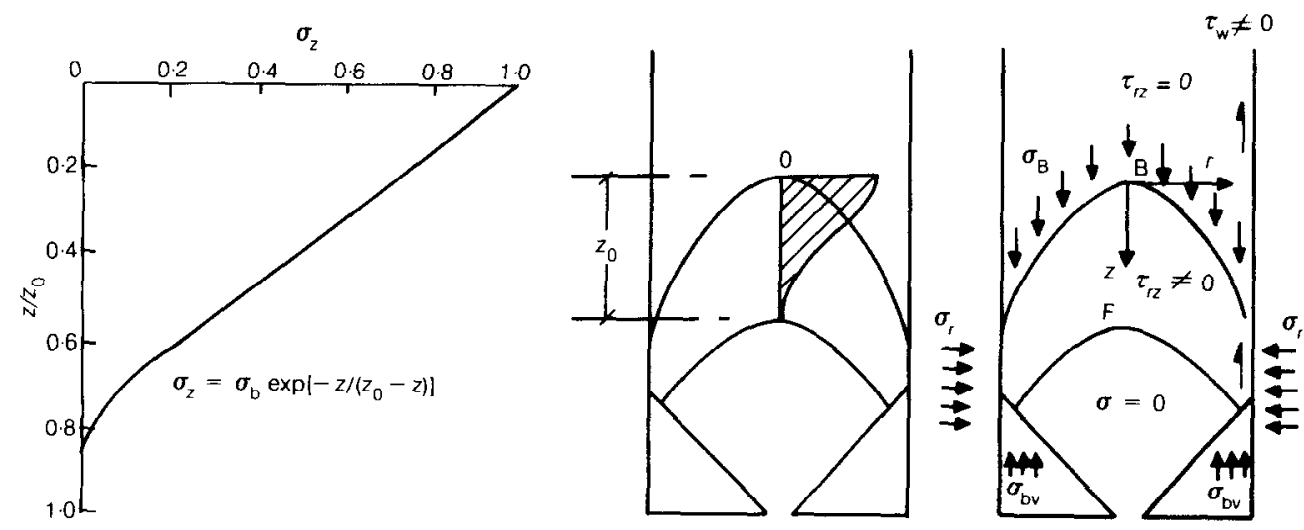

(b)

Fig. 4. (a) Shear stress distribution (theoretical assumption of shear or radial planes); (b) vertical stress distribufion in the plastic zone 


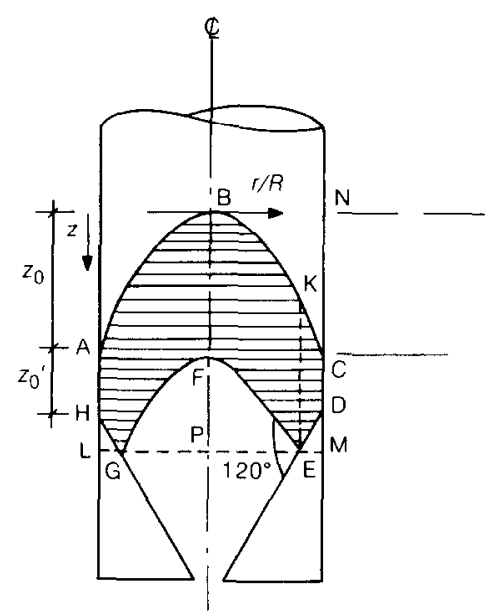

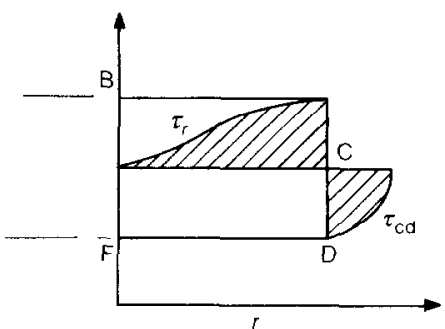

(b)

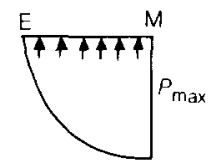

(c)

Fig. 5. (a) Semi-section; (b) shear stress distribution; (c) $P$ diagram

(c) diagrammatic representations of stress distribution in the zone of dynamic equilibrium (plastic flow) based on boundary values in a domain which has upper and lower parabolic surfaces terminating in a vertical (CD) and an oblique (DE) cylindrical surface (Fig. 3).

The stress distribution on the parabolic surfaces $A B C$ and EFG (Figs 4 and 5) are known. The stresses on the vertical surfaces $A H$ and $C D$ and on the oblique surfaces DE and $\mathrm{GH}$ were computed. The problem of stress distribution in the plastic zone or zone of dynamic equilibrium was solved using conformal mapping techniques with the stress function expressed in finite difference form.

The results showed that the increase in both $\sigma_{r}$ and $\sigma_{z}$ at the boundary of the plastic zone is $2.40 \sigma_{r}$ where $\sigma_{r}$ equals Janssen's value for emptying conditions.

The intensity of stress depends on the profile of the mitre of revolution of support in every case, which in turn is a function of grading and of the angle of the exit cone.

\section{REFERENCES}

Chwetzoff (1960). Überdrücke in Silozellen. Etudes et réalisations, No. 75, Nov.-Dec.

Deutsch, G. P. \& Clyde, D. H. (1967). Flow and pres- sure of granular materials in silos. J. Engng Mech. Div. Am. Soc. Civ. Engrs 93, EM6, 103-125.

McCabe, R. P. (1974). Flow patterns in granular material in circular silos. Géotechnique 24 , No. 1 , 45-62.

\section{Author's reply}

Holmberg states that his tabular data give no support to any theory. He has fitted a linear variation of horizontal pressure with depth to the observed pressures in each case and has calculated the corresponding pressure coefficients. His recommended value for what he calls $\delta K_{2}$ is 0.5 . Holmberg therefore seems to accept the applicability of a linear variation of horizontal pressure with depth. Perhaps the point that is missing is that the horizontal pressure coefficient should not be assumed on the basis of an average value but can and should be measured for each material.

Holmberg is quite correct to point out that radial non-uniformity of horizontal pressure will result in bending moments in silo walls that must be catered for in the design and by appropriate location of reinforcing in reinforced concrete silos.

It is important to realize that models of silos are quite worthless as a means of predicting prototype silo behaviour, unless the diameter of the model is at least $1.5 \mathrm{~m}$ and preferably larger. 
Silo action takes place as a result of frictional interaction between the inner surface of the silo wall and the fill material. The zone of interaction extends for a distance of only $200300 \mathrm{~mm}$ or slightly more out from the wall. Hence, in a fullscale silo, the fill-wall interaction zone is of a negligible thickness, compared with the diameter, whereas in a $330 \mathrm{~mm}$ dia. model such as that studied by McCabe the entire cross-section of the silo is strongly affected by interaction with the wall. This is why the zones of concentrated pressure shown in fig. 5 of part I of the Paper (Clague, 1973) and in Fig. 3 do not occur in fullscale silos, unless a cohesive arching of the fill occurs over the opening. Hence McCabe's results, shown in Figs 1-3, are of interest only in so far as they depict the interaction between fill and wall for granular material flowing under gravity through a small diameter tube.

McCabe states that the flow pattern of the material must be established before attempting to measure pressures on the walls of a silo. This is correct, but only in so far that if the silo is not equipped with internal benching of sufficient steepness it is desirable to locate the upper limit to zone 4 of Fig. 2. This limit can be located with sufficient accuracy by assuming that the effective hopper boundary rises at an angle of $45^{\circ}+\phi / 2$ to the horizontal (Blight, 1983)-not at $2 \phi$ as given in Fig. 1.

The Author rejects McCabe's statement that some means of measuring what he calls the 'aggregate horizontal pressure' should be used instead of using individual pressure cells. As figs 14 and 15 of part I of the Paper show, horizontal pressures may not be radially uniform and it is important to recognize this and to assess the extent of the non-uniformity.

The grading of a silo fill is important, but only as a rough index to material behaviour. What is required is a direct measurement of the relevant materials properties - unit weight, angle of wall friction and at-rest pressure coefficient. For very fine powders, the coefficient of consolidation may also be required.

Regarding Janssen's theory, the Paper does not claim anything for the theory but reports that all existing silo design codes are based on it and shows that '...for uninterrupted filling, the arching theory (Janssen's theory with $K=K_{0}$ ) fits the mean of the measurements reasonably well'. The reason for this is that part of the vertical stress in the fill materials, in close proximity to the wall, is transferred into the wall by friction. This reduces the vertical stress and hence the corresponding horizontal stress. The action described takes place whether or not the assumptions McCabe objects to are accurate.

Figure 6 shows this action in a $20 \mathrm{~m}$ dia. steel sugar silo. The figure shows how the wall load and horizontal pressure increase as the sugar overburden is increased. It appears as though $K_{0}$ and $\delta$ remained reasonably constant until a sugar overburden of $105 \mathrm{kPa}$ (12 m depth) was reached. At this stage, no-one would expect any arching, as assumed in the Janssen theory, to be possible. As the overburden increased further, $\delta$ appeared to decrease. Hence the wall load fell and the lateral pressure increased. Even when the overburden was $150 \mathrm{kPa}$, the fill depth was only $17.4 \mathrm{~m}$ and Janssen-type arching could still not be expected. Nevertheless, the interaction between
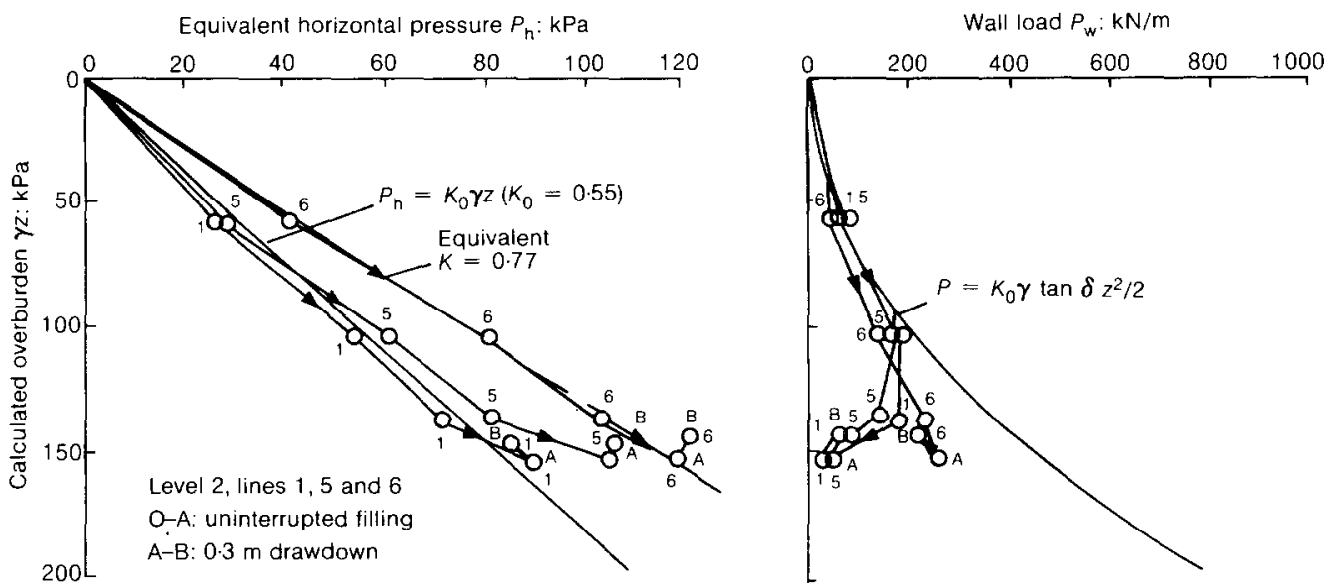

Fig. 6. Build-up of equivalent horizontal pressure and wall load at level 2 in silo during second filling (assumed $\gamma=8 \cdot 6 \mathrm{kN} / \mathrm{m}^{3}$ ) 
the sugar and the wall was very similar to that which would be predicted by the Janssen theory. Fig. 6 is a clear illustration of the powerful effect that the relatively narrow fill-to-wall interaction zone exerts on pressures in full-scale silos.

The Author does not reject all model studies as being irrelevant, only those for which the scale is too small. $\mathrm{He}$ is at present constructing a model silo with a diameter of $1.82 \mathrm{~m}$. The silo has a range of interchangeable hopper sections (cone apex down, cone apex up, flat bottom) and will be used to model the behaviour of the full-scale silos reported in the Papers.
However, if the results of the model tests do not agree with observations of prototype behaviour, the Author will prefer to believe the evidence of the field measurements.

\section{REFERENCES}

Blight, G. E. (1983). Performance of a $20 \mathrm{~m}$ diameter steel maize storage bin. Proc. 2nd Int. Conf. Design of Silos for Strength and Flow, pp. 179-191. London: Powder Advisory Centre.

Clague, K. (1983). The effects of stresses in bunkers. PhD thesis, University of Nottingham. 